\title{
Chemical composition of Galla chinensis extract and the effect of its main component(s) on the prevention of enamel demineralization in vitro
}

\begin{abstract}
Xue-Lian Huang ${ }^{1,2,3}$, Ming-Dong Liu ${ }^{4}$, Ji-Yao $\mathrm{Li}^{1,2}$, Xue-Dong Zhou ${ }^{1,2}$ and Jacob M ten Cate ${ }^{3}$
To determine the chemical composition of Galla chinensis extract (GCE) by several analysis techniques and to compare the efficacy of GCE and its main component(s) in inhibition of enamel demineralization, for the development of future anticaries agents, main organic composition of GCE was qualitatively determined by liquid chromatography-time of flight-mass spectrometry (LC-TOF-MS) and quantified by high-performance liquid chromatography-diode array detector (HPLC-DAD). Inorganic ions were tested by inductively coupled plasma-atomic emission spectroscopy and $\mathrm{F}$ was especially measured by ion chromatography. Then, bovine enamel blocks were randomly divided into four treatment groups and were subjected to a pH-cycling regime for 12 times. Each cycle included 5-min applications with one of four treatments: $4 \mathrm{~g} \cdot \mathrm{L}^{-1} \mathrm{GCE}$ solution, $4 \mathrm{~g} \cdot \mathrm{L}^{-1}$ gallic acid (GA) solution, $1 \mathrm{~g} \cdot \mathrm{L}^{-1} \mathrm{NaF}$ solution (positive control), deionized water (DDW, negative control), and then 60-min application in pH 5.0 acidic buffer and 5-min application in neutral buffer. Acidic buffers were retained for calcium analysis. The main organic composition of GCE were GA and its isomer, and, to a lesser extent, small molecule gallotannins. The content of GA in GCE was $71.3 \% \pm 0.2 \%(w / w)$. Inorganic ions were present in various amounts, of which Ca was $(136 \pm 2.82) \mu \mathrm{g} \cdot \mathrm{g}^{-1}$, and $\mathrm{Zn}$ was $(6.8 \pm 0.1) \mu \mathrm{g} \cdot \mathrm{g}^{-1}$. No $\mathrm{F}$ was detected in GCE. In pH cycling, GA showed an effect similar to GCE in inhibiting enamel demineralization $(P>0.05)$. GA was found to be the main effective, demineralization inhibiting component of GCE and could be a promising agent for the development of anticaries agents.
\end{abstract}

International Journal of Oral Science (2012) 4, 146-151; doi:10.1038/ijos.2012.44; published online 31 August 2012

Keywords: active component; Galla chinensis; gallic acid; composition; dental caries

\section{INTRODUCTION}

Galla chinensis, a traditional Chinese medicine, is widely available and used in China. It originates from the abnormal growth of the Rhus leaf tissue in response to secretion of parasitic aphids (family Pemphigidae). ${ }^{1}$ It has been used for thousands of years due to its antibacterial, antiviral, anticaries, antioxidative, anticancer, liveprotective, antidiabetic, antidiarrheal, anti-inflammatory and antithrombin activity. ${ }^{2}$ G. chinensis is rich in gallotannins, and has nearly $20 \%$ gallic acid (GA) and $7 \%$ methyl gallate. ${ }^{2}$ Gallotannins consist of a central glucose core, which is surrounded by several GA units, and further GA units can be attached through depside bonding of additional galloyl residues. ${ }^{1}$

In recent years, our research group has obtained G. chinensis extract (GCE) with distilled water. GCE was further fractionated by adsorption chromatography with deionized water, $30 \%$ ethanol, $50 \%$ acetone and 100\% acetone successively, and GCE-A, GCE-B, GCE-C and GCE-D were gotten. GCE-B could be further purified and fractionated, and then, GA and methyl gallate were obtained. Among all the extracts from G. chinensis, GCE was demonstrated to be the most effective anticaries agent. GCE was shown to inhibit growth and metabolism of caries pathogens and also favorably shift the demineralization/remineralization balance of enamel. ${ }^{3-10}$ However, previous studies mainly focused on GCE's anticaries activities and on structural changes in enamel when treated by GCE, and paid little attention to the composition analysis and to the main active component(s) in anticaries effects.

It is well documented that traditional Chinese medicine generally possess very complex compositions. Both the choice of raw material and the extraction method will influence the extracts, and thereby can modify their physicochemical characteristics and bioactivities. ${ }^{11}$ For GCE, in studies of the inhibition of enamel demineralization, it was more effective than GCE-A, GCE-B, GCE-C and GCE-D, ${ }^{8}$ suggesting that GCE has more active components due to the extraction method. Quality control is a key issue to guarantee the activities of traditional Chinese medicine. ${ }^{12}$ As a result, in order to benefit the prospective

${ }^{1}$ State Key Laboratory of Oral Diseases, Sichuan University, Chengdu, China; ${ }^{2}$ West China Hospital of Stomatology, Sichuan University, Chengdu, China; ${ }^{3}$ Department of Cariology Endodontology Pedodontology, Academic Centre for Dentistry Amsterdam (ACTA), University of Amsterdam and Free University Amsterdam, Amsterdam, The Netherlands and ${ }^{4}$ Department of Analytical Toxicology, West China School of Preclinical and Forensic Medicine, Sichuan University, Chengdu, China

Correspondence: Professor XD Zhou, Department of Endodontics and Operative Dentistry, West China School of Stomatology, No 14, Section 3, Renmin South Road, Chengdu 610041, China

E-mail: zhouxd@scu.edu.cn

Professor JM ten Cate, Department of Cariology Endodontology Pedodontology, Academic Centre for Dentistry Amsterdam (ACTA), Gustav Mahlerlaan 3004, Amsterdam 1081LA, The Netherlands

E-mail: J.t.cate@acta.nl

Received 15 January 2012; accepted 30 May 2012 

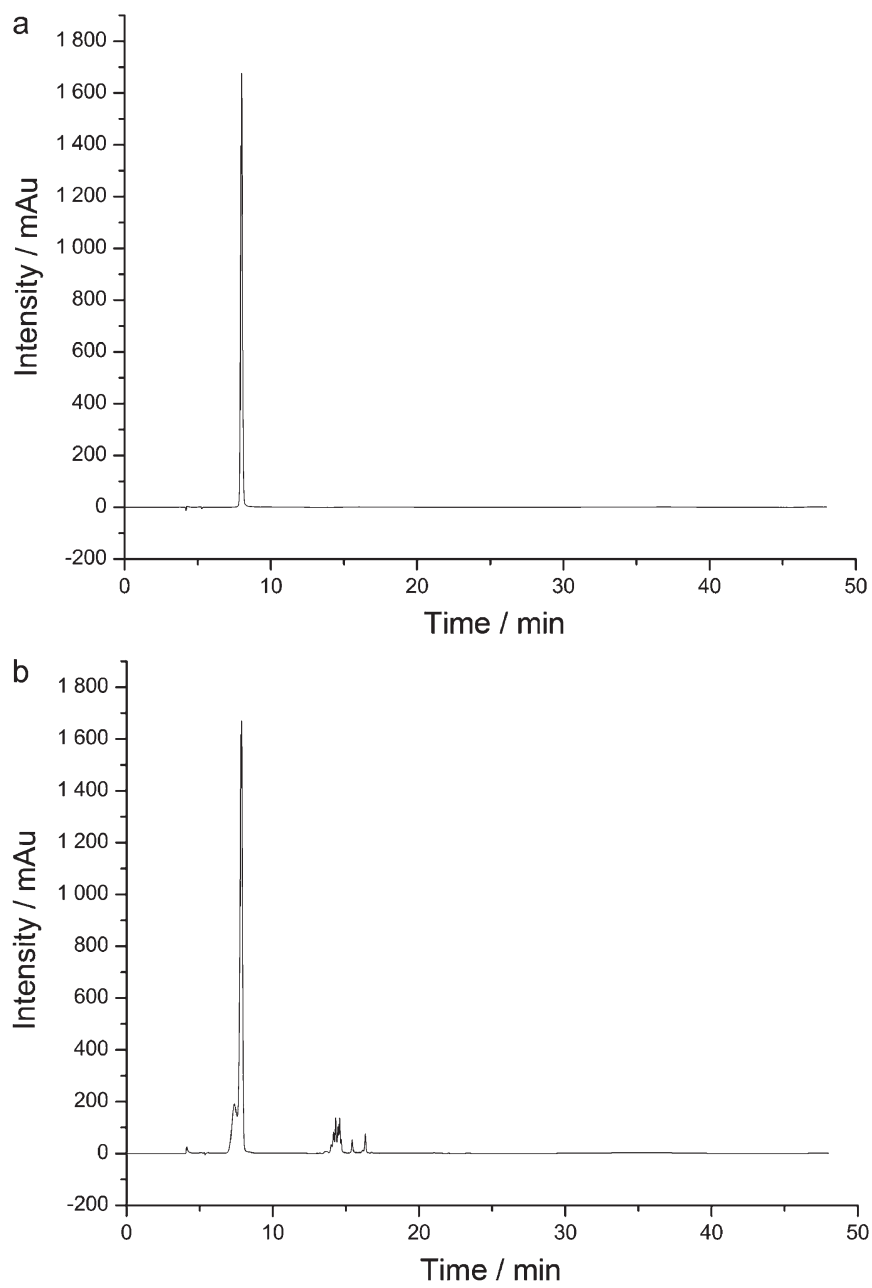

Figure 1 HPLC-DAD chromatograms. (a) Gallic acid at $270 \mathrm{~nm}$. (b) GCE at $270 \mathrm{~nm}$. GCE, Galla chinensis extract; HPCL-DAD, high-performance liquid chromatography-diode array detector.

clinic applications, GCE, the most effective extract, was chosen to be explored.

The present study focuses on the main active component of GCE for the following reasons: (i) it would be more efficient to control quality if this could focus on one or more active components; (ii) one could synthesize the active component(s) in order to obtain more products at lower cost, such as for the synthesis of quinine; ${ }^{13}$ (iii) one might modify the active molecule(s) to improve physicochemical properties and facilitate formulation of a product. For example, artemisinin, an extract from Artemesia annua, was largely replaced by dihydroartemisinin and its derivatives artesunate and artemether, which have greater antimalarial activities. ${ }^{14}$

The aim of the current study was to determine GCE's chemical composition and to compare the efficacy of GCE and its main component(s) in inhibition of enamel demineralization, thereby benefiting the practical anticaries applications of GCE

\section{MATERIALS AND METHODS}

\section{G. chinensis extract}

G. chinensis (origin: Sichuan Province, China) was purchased from China Tong Ren Tang drugstore (Chengdu, China). GCE was extracted as described in previous studies. ${ }^{3-10}$ G. chinensis $(1 \mathrm{~kg})$ was dried in an oven at $60{ }^{\circ} \mathrm{C}$ for 3 days, finely powdered and added to $600 \mathrm{~mL}$ of distilled water. The mixture was stirred for $10 \mathrm{~h}$ at $65{ }^{\circ} \mathrm{C}$ and then filtered. The extract was re-extracted with distilled water under the same conditions. Then the extract was dissolved in $500 \mathrm{~mL}$ of ethanol (95\%). After filtration and evaporation, the remaining extract was lyophilized to give a powder.

Liquid chromatography-time of flight-mass spectrometry analysis Main organic composition of GCE was qualitatively determined by liquid chromatography-time of flight-mass spectrometry (LC-TOFMS), a tandem system. The Agilent 1200 series (Agilent Technologies, Santa Clara, CA, USA) high-performance liquid chromatography (HPLC) consisted of a model G1315D diode array detector (DAD), a G1312B binary pump, a G1379B vacuum degasser, a G1367C autosampler and a G1316B column heater. The concentration of GCE tested was $1 \mathrm{mg} \cdot \mathrm{mL}^{-1}$, and the injection volume was $5 \mu \mathrm{L}$. Gradient elution HPLC was applied at a flow rate of $0.4 \mathrm{~mL} \cdot \mathrm{min}^{-1}$ with detection at $270 \mathrm{~nm}$. Two solvents were used for the mobile phase: (A) $0.1 \%$ formic acid and $10 \mathrm{~mol} \cdot \mathrm{L}^{-1}$ ammonium formate ( $\mathrm{pH} 3.0$ ) and (B) acetonitrile. Compounds were separated using the following gradient: 0-5 min, 5\% B; 5-8 min, 20\% B; 20-30 min, 30\% B; 30-40 min, 20\% B; 40.0-40.1 min, 5\% B. The separation of components in GCE was performed on an Agilent column (Poroshell 120 SB-C18, $150 \mathrm{~mm} \times$ $4.6 \mathrm{~mm}$, particle size $2.7 \mu \mathrm{m})$ at $40{ }^{\circ} \mathrm{C}$.

The TOF mass detector (G1969A; Agilent Technologies, Santa Clara, CA, USA) was equipped with electrospray ionization interface. The electrospray ionization voltage was $3.5 \mathrm{kV}$, and a mass range of $50-3000 \mathrm{~m} / z$ was scanned in negative full scan mode. Data processing was performed on Agilent Mass Hunter (v.B.01.04) software.

\section{Determination of GA content in GCE}

As the GA peak was very obvious in HPLC-DAD chromatograms (shown in Figure 1), GA content in GCE was further quantified by HPLC-DAD. The gradient elution HPLC conditions were the same with LC-TOF-MS analysis. Flow rate was $0.4 \mathrm{~mL} \cdot \mathrm{min}^{-1}$, and detection wavelength was $270 \mathrm{~nm}$. The injection volume was $10 \mu \mathrm{L}$. Data processing was performed on CHEMSTATION (v.B.04.02) software. GA (reference substance) in all the studies was purchased from the National Institute for the Control of Pharmaceutical and Biological Products (Chengdu, China).

\section{Determination of inorganic ions}

Inorganic ions were determined by inductively coupled plasmaatomic emission spectroscopy (ICP-AES) (Spctro Arcos Eop, Kleve, Germany). About $0.5 \mathrm{~g}$ G. chinensis powder was digested in concentrated $\mathrm{HNO}_{3}$ in microwave oven. Digests were made up to $25 \mathrm{~mL}$ and each analysis was performed in triplicate. Considering that fluoride is an effective anticaries agent, ${ }^{15}$ the fluoride content of GCE was determined with a Dionex ICS-2100 ion chromatography system (Dionex ICS-2100, Dionex, Sunnyvale, CA, USA) equipped with a GS50 gradient pump, EGC eluent generator, AS-DV autosampler, LC30 thermal compartment and a $4-\mathrm{mm}$ anion self-regenerating suppressor (ASRS 300) operated in the external water mode (Dionex, Sunnyvale, CA, USA). Chromeleon SE chromatography software was used for system control. About $40 \mathrm{mg}$ GCE or GA was dissolved in MilliQ water, adjusted to a final volume of $10 \mathrm{~mL}$, and filtrated with a $0.22 \mu \mathrm{m}$ filter; $25 \mu \mathrm{L}$ injection was separated using an IonPac AS15 column $(250 \mathrm{~mm} \times 4 \mathrm{~mm}$; Dionex $)$. A standard curve was gotten from a serial of $\mathrm{NaF}$ solutions with different concentrations. 


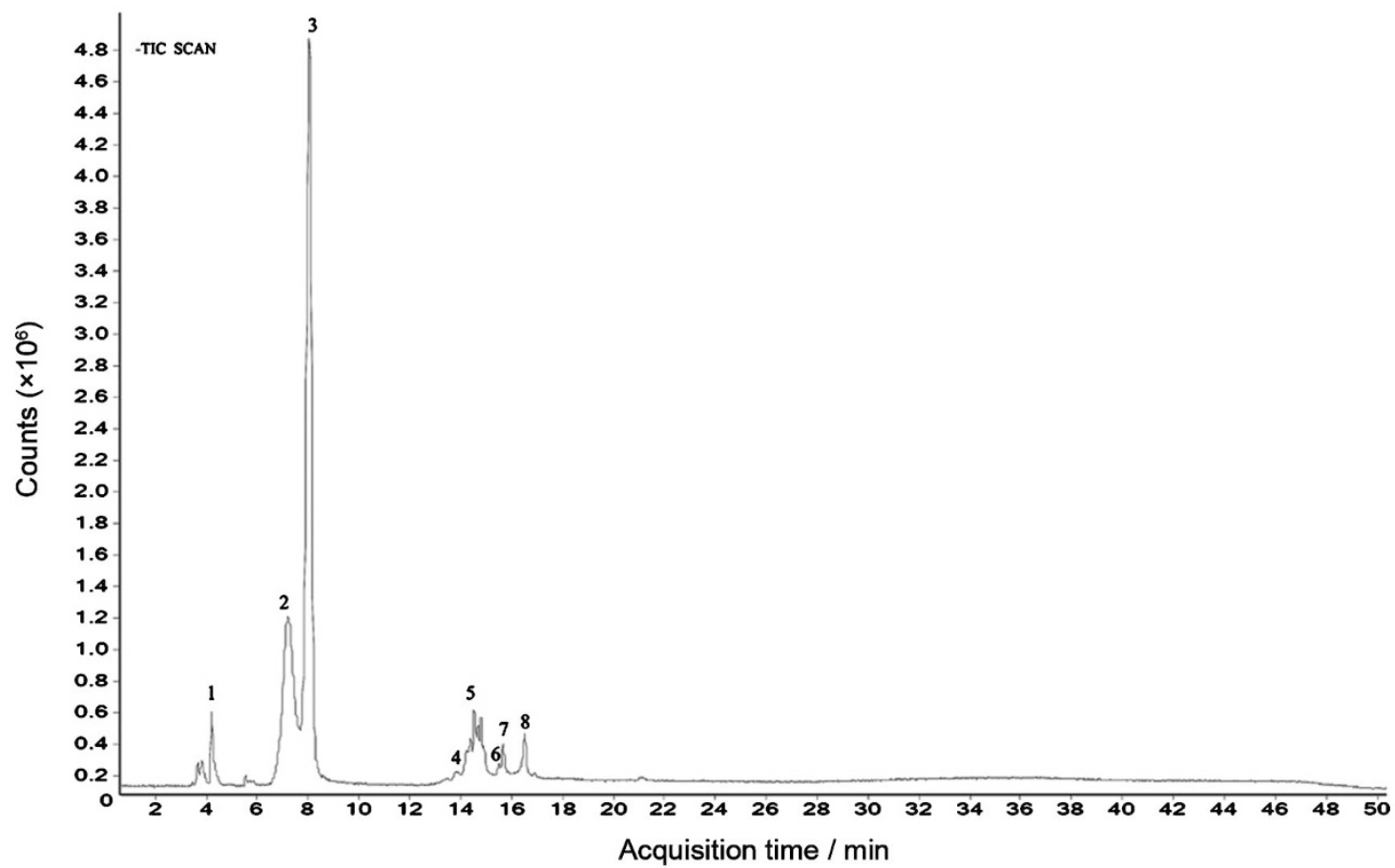

Figure 2 GCE total ion current chromatography obtained from LC-TOF-MS. GCE, Galla chinensis extract; LC-TOF-MS, liquid chromatography-time of flight-mass spectrometry.

\section{Effects on demineralization of bovine enamel}

Bovine enamel specimens were prepared and the baseline surface microhardness was measured as in previous studies. ${ }^{4-5,8}$ Then, 40 specimens were selected from a batch of 420 specimens, each with baseline surface microhardness between 388.7 and 436.1 Knoop hardness number.

The specimens were randomly divided into the following four different test solution groups (each $N=10$ ): $4 \mathrm{~g} \cdot \mathrm{L}^{-1}$ GCE solution ( $\mathrm{pH} 5.5), 4 \mathrm{~g} \cdot \mathrm{L}^{-1} \mathrm{GA}$ solution( $\left.\mathrm{pH} 5.5\right), 1 \mathrm{~g} \cdot \mathrm{L}^{-1} \mathrm{NaF}$ solution (positive control) and deionized water (DDW, negative control).

Next, specimens were $\mathrm{pH}$-cycled following the procedure described in a previous study. ${ }^{8}$ In brief, after immersion of the specimens in one of the test solutions for $5 \mathrm{~min}$, the blocks were placed in an acidic buffer $\left(50 \mathrm{mmol} \cdot \mathrm{L}^{-1}\right.$ acetic acid, $1.5 \mathrm{mmol} \cdot \mathrm{L}^{-1}$ potassium dihydrogen orthophosphate, $\mathrm{pH} 5.0)$ for $1 \mathrm{~h}$ ( $2 \mathrm{~mL}$ per block), and then in a neutral buffer $\left(20 \mathrm{mmol} \cdot \mathrm{L}^{-1} 4\right.$-(2-hydroxyethyl)-1-piperazineethanesulfonic acid (HEPES), $1.5 \mathrm{mmol} \cdot \mathrm{L}^{-1}$ potassium dihydrogen orthophosphate, $\mathrm{pH} 7.0$ ) for $5 \mathrm{~min}$ ( $2 \mathrm{~mL}$ per block) in each of 12 cycles. After test solution treatment, specimens were washed with DDW three times for $1 \mathrm{~min}$, and after acidic buffer or neutral buffer treatment, specimens was washed for $1 \mathrm{~min}$. This cycle was repeated twice daily for 6 days. During the remaining time, the specimens were placed in neutral buffer.

After $\mathrm{pH}$ cycling, the acidic buffers were retained for analysis. Calcium concentration in the acidic solutions was determined using atomic absorption spectrophotometry (AAS) (Thermo Element MKII-M6; Thermo Electron, Waltham, MA, USA). Then a calcium depletion rate (CDR) for each sample was calculated. ${ }^{16}$ This is a measure of calcium extracted per unit area per unit time per $1 \mathrm{~mL}$ acid and is calculated as

$$
C D R=\frac{\text { mass of calcium extracted }}{(\text { time in acid })(\text { area exposed })} \quad\left(\mu \mathrm{g} \cdot \mathrm{h}^{-1} \cdot \mathrm{mm}^{-2}\right)
$$

\section{Statistical analysis}

Statistical evaluations were performed using the SPSS 16.0 software (SPSS Incorporated, Chicago, IL, USA). The normal distribution of the data was tested with the Kolmogorov-Smirnov tests. Data were analyzed with one-way ANOVA followed by post hoc least significant difference (LSD) tests, with the level of significance set at $5 \%$.

\section{RESULTS}

\section{LC-TOF-MS analysis}

HPLC-DAD chromatograms demonstrated that GCE consists of several components (Figure 1), which was also revealed by total ion current chromatography (Figure 2), and further indentified by mass spectra (Figure 3). In detail, the main molecular mass ranges, corresponding compounds and $\mathrm{m} / \mathrm{z}$ values observed from negative ion experiments with LC-TOF-MS for the GCE are shown in Table 1.

The $m / z$ values revealed that GCE were mixtures, consisting mainly of GA and its isomer, and 1-3GGs, which were galloylglucopyranose (1GG), di-galloylglucopyranose (2GG), tri-galloylglucopyranose (3GG), respectively.

\section{Determination of GA content in GCE}

Regression equations for the GA were obtained by plotting the peak area of GA ( $y$ axis) vs. GA concentration $\left(1.09-436.61 \mu \mathrm{g} \cdot \mathrm{mL}^{-1}, x\right.$ axis): $y=77.64 x-43.52, r=0.9999$. This way GCE was calculated to contain $71.3 \% \pm 0.2 \%(w / w)$ GA, which showed GA to be the major component of GCE.

\section{Determination of inorganic ions}

The data in Table 2 showed that inorganic ions were present in various amounts, of which Ca was $(136 \pm 2.82) \mu \mathrm{g} \cdot \mathrm{g}^{-1}$, comprised the largest amount. G. chinensis also contained $(6.8 \pm 0.1) \mu \mathrm{g} \cdot \mathrm{g}^{-1} \mathrm{Zn}$, which is 
a
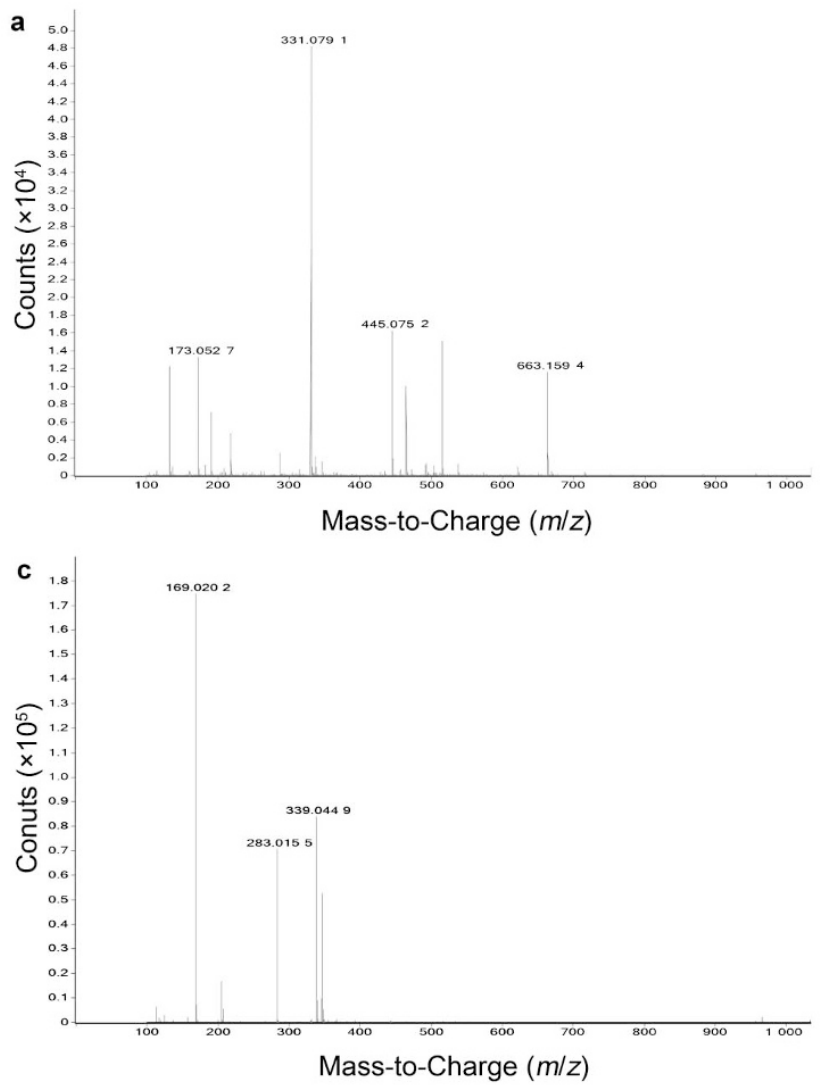

e
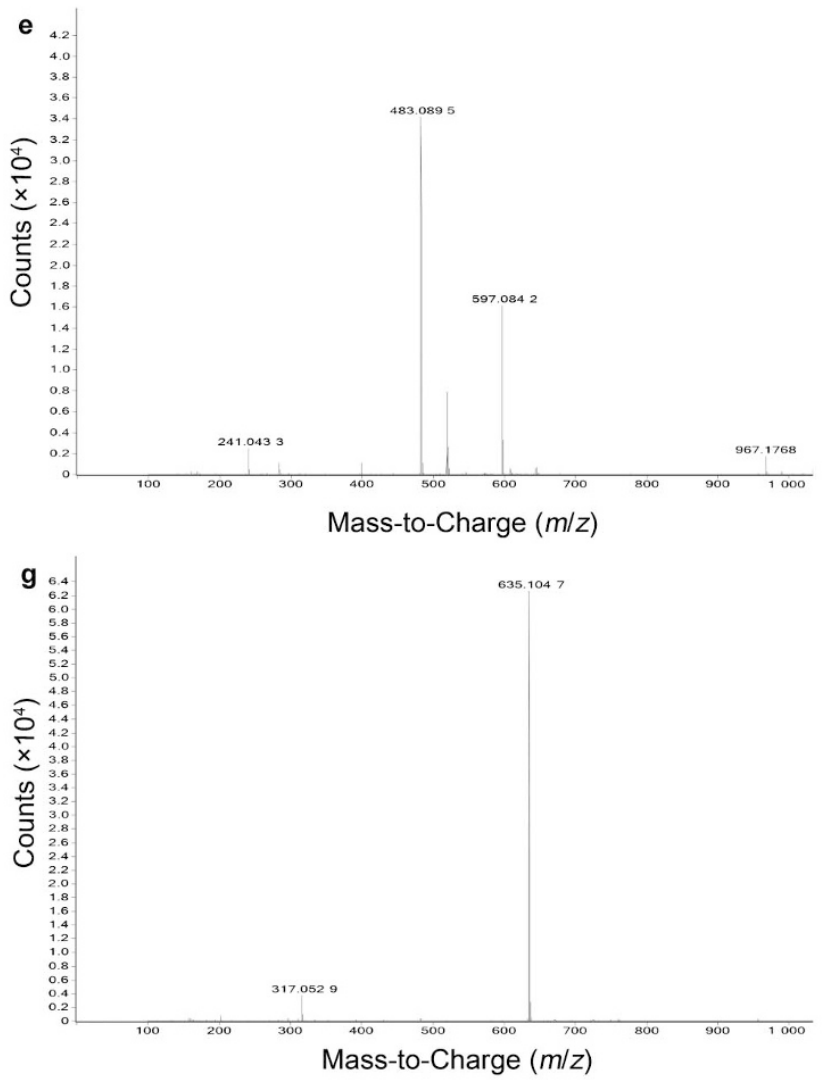
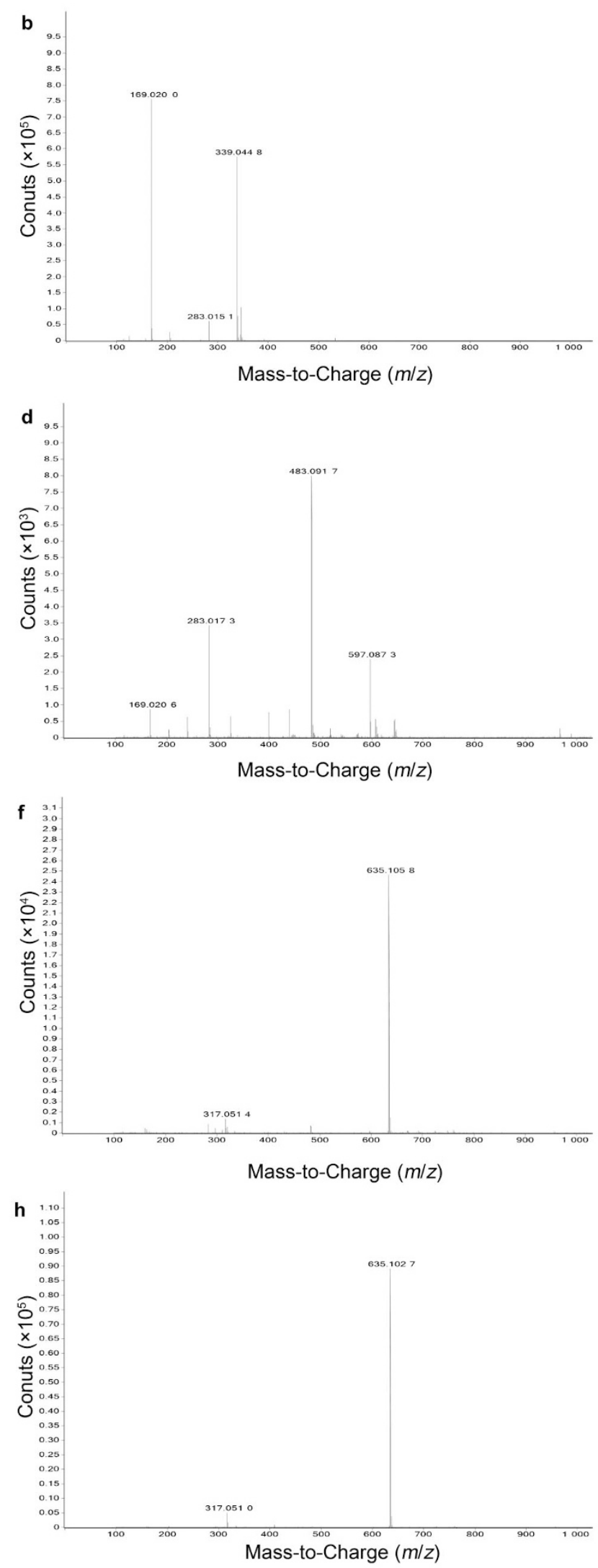

Figure 3 Negative mass spectra of the eight main compounds. a-h, show the corresponding spectrum of peaks 1-8 in Figure 2 respectively. 
Table 1 The main $m / z$ values observed from negative full scan with LC-TOF-MS for GCE

\begin{tabular}{lll}
\hline Peak & Main observed masses of LC-TOF-MS $(\mathrm{m} / \mathrm{z})^{\mathrm{a}}$ & $\begin{array}{l}\text { Corresponding } \\
\text { compounds }^{\mathrm{b}}\end{array}$ \\
\hline 1 & $663.1594[2 \mathrm{M}-\mathrm{H}]^{-}, 331.0791[\mathrm{M}-\mathrm{H}]^{-}$ & $1 \mathrm{GG}$ \\
2 & $339.0448[2 \mathrm{M}-\mathrm{H}]^{-}, 169.0200[\mathrm{M}-\mathrm{H}]^{-}$ & $\mathrm{GA}$ isomer \\
3 & $339.0449[2 \mathrm{M}-\mathrm{H}]^{-}, 169.0202[\mathrm{M}-\mathrm{H}]^{-}$ & $\mathrm{GA}$ \\
4 & $483.0917[\mathrm{M}-\mathrm{H}]^{-}$ & $2 \mathrm{GG}$ \\
5 & $483.0895[\mathrm{M}-\mathrm{H}]^{-}$ & $2 \mathrm{GG}$ isomer \\
6 & $635.1058[\mathrm{M}-\mathrm{H}]^{-}$ & $3 \mathrm{GG}$ \\
7 & $635.1047[\mathrm{M}-\mathrm{H}]^{-}$ & $3 \mathrm{GG}$ isomer \\
8 & $635.1027[\mathrm{M}-\mathrm{H}]^{-}$ & $3 \mathrm{GG}$ isomer \\
\hline
\end{tabular}

GCE, Galla chinensis extract; LC-TOF-MS, liquid chromatography-time of flightmass spectrometry.

a The mass spectrometry was worked at least $2 \mu \mathrm{g} \cdot \mathrm{g}^{-1}$ accuracy.

b $1-3 G G s$ represented galloylglucopyranose, di-galloylglucopyranose and trigalloylglucopyranose, respectively.

Table 2 The inorganic ions of Galla chinensis obtained by ICP-AES

\begin{tabular}{lc}
\hline Component & Content $/\left(\mu \mathrm{g} \cdot \mathrm{g}^{-1}\right)(\mathrm{mean} \pm \mathrm{s} . \mathrm{d})$. \\
\hline $\mathrm{Ca}$ & $136 \pm 2.82$ \\
$\mathrm{Cr}$ & $0.21 \pm 0.01$ \\
$\mathrm{Fe}$ & $15.8 \pm 0.26$ \\
$\mathrm{Mn}$ & $3.1 \pm 0.08$ \\
$\mathrm{P}$ & $12.3 \pm 0.21$ \\
$\mathrm{Sn}$ & $0.95 \pm 0.06$ \\
$\mathrm{Zn}$ & $6.8 \pm 0.12$ \\
\hline
\end{tabular}

ICP-AES, inductively coupled plasma-atomic emission spectroscopy.

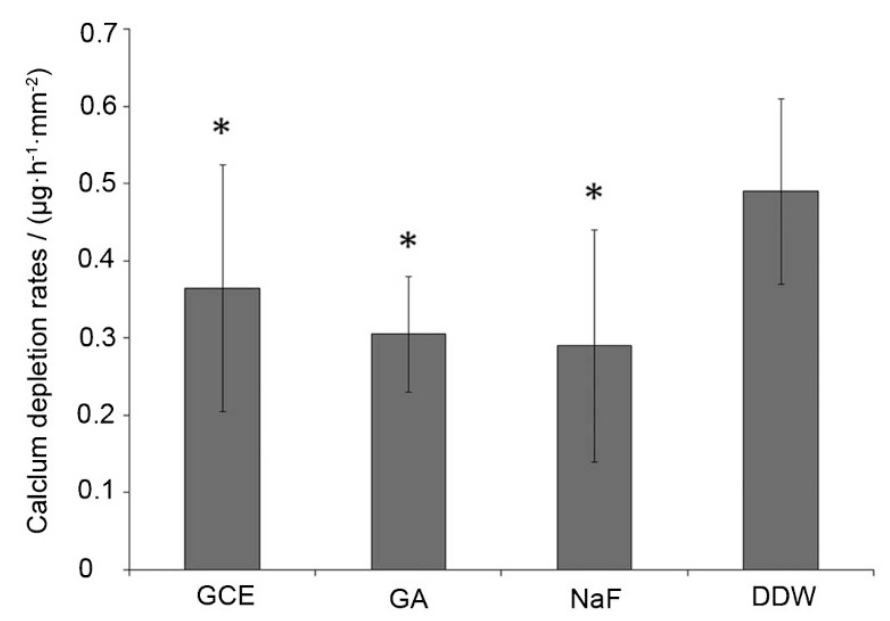

Figure 4 CDRs in acidic buffers after pH-cycling regimen. CDR, calcium depletion rate.

important to note as $\mathrm{Zn}$ is a bacteriostatic agent. ${ }^{17}$ No F was present in GCE or GA.

Effects on demineralization of bovine enamel

The average data of CDR are presented in Figure 4. CDR values were lower in the GCE and GA groups than in DDW group, with significant differences between GCE group and DDW group $(P<0.05)$, and between GA group and DDW group $(P<0.001)$. Although CDR values were lower in GA group than in GCE group, this difference was not statistically significant $(P>0.05)$.

\section{DISCUSSION}

In HPLC, gradient elution refers to a continuous change in the mobile phase during separation, and then the retention of later peaks is continually reduced. ${ }^{18}$ HPLC combined with MS detection is one of the most versatile analytical techniques used for the characterization of phenol compounds. ${ }^{19}$ The online coupling of HPLC with MS using electrospray ionization is developed because of its efficient resolution and identification of a wide range of polar compounds. TOF-MS can provide accurate mass data over a wide dynamic range and thereby permits the rapid and reliable assessment of the elemental composition of ions. ${ }^{19}$

Combining the LC-TOF-MS data and the main $\mathrm{m} / \mathrm{z}$ values of polyphenols in G. chinensis, ${ }^{20}$ we were able to determine the main organic composition of GCE. Based on the HPLC-DAD data, we concluded that GA was the major component of GCE. In addition, we noted that our GCE was quite different in composition from other GCEs: Tian and colleagues reported primarily 1-10GGs from their extracts from G. chinensis, ${ }^{20}$ while the commercially available extracts from G. chinensis, which is always called Chinese gallotannins, was reported to consist mainly of $3-14 \mathrm{GGs} .{ }^{21}$ We presumed that these differences in main organic composition should be attributed to the extraction method.

Also inorganic ions could in part be responsible for the clinic effects of natural medicines. In our study, calcium ions were found to make up the largest proportion in inorganic ions. Calcium is also present in saliva and needed for the re-mineralization of the dental hard tissues. Calcium could have combined effects with organic components of GCE, but this possible synergism needs to be further explored. Metal ions may have an effect on bacteria, such as $\mathrm{Zn}$, which can inhibit acid production of Streptococcus mutans at concentration as low as $0.01-0.1 \mathrm{mmol} \cdot \mathrm{L}^{-1} \cdot{ }^{17}$ No $\mathrm{F}$ was present in GCE or GA, indicating that the main active component(s) of GCE in anticaries activities is rather than $\mathrm{F}$.

In previous studies, GCE was demonstrated to be more effective than GA in remineralization, according to the data of surface microhardness recovery (\%SMHR). ${ }^{5}$ However, in the present study, we did not find the significant differences in inhibiting enamel demineralization between GCE and GA. Considering that GA was shown to be the main component of GCE, combined with the observed similar enamel demineralization inhibiting effects of GCE and GA, this suggests that GA is the component of GCE which is primarily responsible for the inhibition of enamel demineralization.

The process of enamel demineralization involves the dissolution of enamel apatite crystals, and the diffusion of ions, in particular calcium, phosphate and hydrogen ions, into and out of the enamel microstructure. It has been suggested that diffusion in enamel is controlled by the organic matrix network, which occupies both the inter- and intraprismatic spaces ${ }^{22}$ and even appears on the surface of enamel, such as perikymata. ${ }^{23}$ The organic matrix of mature enamel mainly consists of proteins, such as enamelin, tuftelin and sheathlin. ${ }^{23}$ Changes in structure affect the process of the enamel demineralization by modification of the diffusion pathway inside the tooth structures. $^{24}$ In a previous study, GCE's anti-demineralization effects were presumably attributed to its ability to precipitate proteins, ${ }^{8}$ and the organic matrix of enamel was demonstrated to play a substantial role. ${ }^{9}$

Several factors influence the interaction of polyphenols and proteins, such as molecular weight, molecular conformation, molecular proportion of polyphenols and proteins, $\mathrm{pH}$ and inorganic ions. ${ }^{11}$ When solutions containing GA come into contact with enamel, cal- 
cium ions form cross-links with GA, and thereby influence the precipitation with various enamel proteins. Such phenomena have been observed frequently: in bayberry juice haze, which comprises mainly protein-tannin haze, high amount of GA, calcium and proteins were found in the sediment. ${ }^{25}$

Apart from inhibiting enamel demineralization effect we observed in the present study, GA was demonstrated to enhance remineralization of initial enamel lesion ${ }^{4,10}$ and inhibit metabolism of oral bacteria, ${ }^{26}$ suggesting that it could be a potential source for the development of promising anticariogenic agents. In particular, GA is reported to have antioxidant, antimutagenic and anticarcinogenic activities. It is expected to reduce the risk of disease and bring health benefits in cases of daily intake. ${ }^{27}$ Therefore, GA could help to improve dental health if added to food and/or beverages.

There were much less small molecule gallotannins in GCE compared with GA. Either isolating from $G$. chinensis or obtaining from chemical synthesis, it is very hard and expensive to get $1-3 \mathrm{GGs} .{ }^{28}$ As the clinical significance of the present study was to benefit the practical anticaries applications of GCE, the effects in inhibiting enamel demineralization of 1-3GGs are of little significance.

G. chinensis is rich in gallotannins. To some degree, large moleculer gallotannins have stronger binding affinity to proteins, ${ }^{29}$ and the effect of large moleculer gallotannins on inhibiting demineralization and enhancing remineralization is little known. The potential effects of large molecular gallotannins could be explored in the future study.

The present study analyzed the main organic composition and inorganic ions in GCE. Combining the effect in pH cycling, GA was the main active component in inhibition of enamel demineralization. GA is suggested to be the main effective constituent of GCE in inhibiting enamel demineralization.

\section{ACKNOWLEDGEMENTS}

This research was supported by the National Natural Science Foundation of China (grant nos. 30572409 and 30430800) and Youth Foundation of Sichuan Province in China (grant no. 07ZQ026-020). The authors are grateful to the West China School of Pharmacy, Sichuan University for providing technical assistance in G. chinensis extraction and fractionation.

1 Tian F, Li B, Ji B et al. Identification and structure-activity relationship of gallotannins separated from Galla chinensis. LWT-Food Sci Technol 2009; 42(7): 1289-1295.

2 Djakpo O, Yao W. Rhus chinensis and Galla chinensis - folklore to modern evidence: review. Phytother Res 2010; 24(12): 1739-1747.

3 Cheng L, Exterkate RA, Zhou X et al. Effect of Galla chinensis on growth and metabolism of microcosm biofilms. Caries Res 2011; 45(2): 87-92.

4 Cheng L, Li JY, Hao YQ et al. Effect of compounds of Galla chinensis and their combined effects with fluoride on remineralization of initial enamel lesion in vitro. $J$ Dent 2008; 36(5): 369-373.

5 Chu JP, Li JY, Hao YQ et al. Effect of compounds of Galla chinensis on remineralisation of initial enamel carious lesions in vitro. J Dent 2007; 35(5): 383-387.
6 Xie Q, Li J, Zhou X. Anticaries effect of compounds extracted from Galla Chinensis in a multispecies biofilm model. Oral Microbiol Immunol 2008; 23(6): 459-465.

7 Huang S, Gao S, Cheng L et al. Combined effects of nano-hydroxyapatite and Galla chinensis on remineralisation of initial enamel lesion in vitro. J Dent 2010; 38(10): 811-819.

8 Zou L, Zhang LL, Li JY et al. Effect of Galla chinensis extract and chemical fractions on demineralization of bovine enamel in vitro. J Dent 2008; 36(12): 999-1004.

9 Zhang LL, Xue J, Li JY et al. Effects of Galla chinensis on inhibition of demineralization of regular bovine enamel or enamel disposed of organic matrix. Arch Oral Biol 2009; 54(9): 817-822.

10 Cheng L, ten Cate JM. Effect of Galla chinensis on the in vitro remineralization of advanced enamel lesions. Int J Oral Sci 2010; 2(1): 15-20

11 Shi B, Di Y. Plant polyphenol. Beijing: Science Press, 2000: 30-31, 70-81, 102105.

12 Jiang $\mathrm{Y}$, David B, Tu $\mathrm{P}$ et al. Recent analytical approaches in quality control of traditional Chinese medicines-a review. Anal Chim Acta 2010; 657(1): 9-18.

13 Ball P. History of science: quinine steps back in time. Nature 2008; 451(7182): 1065-1066.

14 White NJ. Qinghaosu (Artemisinin): the price of success. Science 2008; 320(5874): 330-334.

15 ten Cate JM, Buijs MJ, Miller CC et al. Elevated fluoride products enhance remineralization of advanced enamel lesions. J Dent Res 2008; 87(10): 943-947.

16 ten Cate JM, Duijsters PP. Influence of fluoride in solution on tooth demineralization. Caries Res 1983; 17(6):193-199.

17 Phan TN, Buckner T, Sheng J et al. Physiologic actions of zinc related to inhibition of acid and alkali production by oral streptococci in suspensions and biofilms. Oral Microbiol Immunol 2004; 19(1): 31-38.

18 Snyder LR, Dolan JW. High-performance gradient elution: the practical application of the linear-solvent-strength model. Hoboken: Wiley Interscience, 2007.

19 Iswaldi I, Arráez-Román D, Rodríguez-Medina I et al. Identification of phenolic compounds in aqueous and ethanolic rooibos extracts (Aspalathus linearis) by HPLC-ESI-MS (TOF/IT). Anal Bioanal Chem 2011; 400(10): 3643-3654.

20 Tian F, Li B, Ji B et al. Antioxidant and antimicrobial activities of consecutive extracts from Galla chinensis: the polarity affects the bioactivities. Food Chem 2009; 113(1): 173-179.

21 Xiang $\mathrm{P}$, Lin $\mathrm{Y}$, Lin $\mathrm{P}$ et al. Effect of cationization reagents on the matrix-assisted laser desorption/ionization time-of-flight mass spectrum of Chinese gallotannins. J Appl Polym Sci 2007; 105(2): 859-864.

22 Travis DF, Glimcher MJ. The structure and organization of, and the relationship between the organic matrix and the inorgainc crystals of embrayonic bovine enamel. J Cell Biol 1964; 23(3): 447-497.

23 Yu S. Oral histology and pathology. 6th ed. Beijing: People's Medical Publishing House, 2007: 47-48.

24 Featherstone JD, Rosenberg H. Lipid effect on the progress of artificial carious lesions in dental enamel. Caries Res 1984; 18(1): 52-55.

25 Fang Z, Zhang M, Tao G et al. Chemical composition of clarified bayberry (Myrica rubra Sieb. et Zucc.) juice sediment. J Agric Food Chem 2006; 54(20): 7710-7716.

26 Kang MS, Oh JS, Kang IC et al. Inhibitory effect of methyl gallate and gallic acid on oral bacteria. J Microbiol 2008; 46(6): 744-750.

27 Hsu CL, Yen GC. Effect of gallic acid on high fat diet-induced dyslipidaemia, hepatosteatosis and oxidative stress in rats. Br J Nutr 2007; 98(4): 727-735.

$28 \mathrm{He} \mathrm{Q}$, Shi B, Yao K et al. Synthesis of 6-O-galloyl-D-glucose, 3,6-di-O-galloyl-Dglucose and 3,4,6-tri-O-galloyl-D-glucose. J Sichuan Univ (Eng Sci Edition) 2002; 34(3): 110-113.

$29 \mathrm{He}$ Q, Shi B, Yao K. Interactions of gallotannins with proteins, amino acids, phospholipids and sugars. Food Chem 2006; 95(2): 250-254.

This work is licensed under a Creative Commons Attribution-NonCommercial-NoDerivative Works 3.0 Unported License. To view a copy of this license, visit http:// creativecommons.org/licenses/by-nc-nd/3.0 